\title{
Single-step PCR-based genetic sex determination of rat tissues and cells
}

\author{
Pramod Dhakal and Michael J. Soares \\ Institute for Reproductive Health and Regenerative Medicine, \\ Department of Pathology \& Laboratory Medicine and Department \\ of Pediatrics, University of Kansas Medical Center, Kansas City, KS
}

BioTechniques 62:232-233 (May 2017) doi 10.2144/000114548

Keywords: rat, fetal, sex determination

The advent of genome editing strategies has expanded the range of animal models available for gene manipulation and renewed research interest in the rat. Gender is a key variable for in vivo gene function analyses. Here, we present a simple PCR-based method to determine genetic sex in the rat.

Historically, the rat has been an important animal model for biomedical research in the field of reproductive physiology, including the dissection of mechanisms controlling hemochorial placentation (1). Over the past few decades, the absence of effective tools for manipulating the rat genome limited its utility for in vivo experimentation. However, recent advances in genome editing strategies have expanded the utility of under-utilized animal models for in vivo mechanistic analyses and have rekindled interest in the rat (2).

Recognition of gender-specific phenotypes has drawn the attention of researchers world-wide, and gender has emerged as an important variable in pregnancy research (3). Sexual dimorphism exists in fetal and placental development, adaptations to environmental challenges, and vulnerability to pregnancy-related disease states (4-9). Postnatally, the sex of a rat can be determined by visual inspection of the external genitalia. External landmarks (distance between the anus and the external genitalia) can be used to distinguish male versus female pups within a few days after birth. There are also sex chromosome-specific behaviors in certain cell culture lines, including trophoblast stem (TS) cells (10), necessitating biochemical/molecular approaches for sex determination.

Traditionally, sex chromosome status has been biochemically assessed using PCR amplification of the $Y$ chromosome-specific Sry gene $(11,12)$, but this approach has inherent difficulties due to the absence of an internal control for the female genome. Several different single-step PCR-based methods have been established to identify the sex chromosome status of mice utilizing primer sets designed to amplify specific genes on the $X$ and $Y$ chromosomes, yielding distinct amplicons (13-15). However, no such protocols have been reported for genetic sex determination in rats.

To address this deficit, we developed and validated a single-step PCR method using three primers to identify the genetic sex of rat tissues and cells. Our method is a modification and improvement of the protocol described by Clapcote and Roder for mice (13).
The mouse procedure is based on the amplification of $\mathrm{X}$ chromosome ( $\mathrm{Kdm} 5 \mathrm{c}$ ) and $Y$ chromosome $(K d m 5 d)$ specific genes, which possess significant sequence identity (13). Two common primers are used to amplify mouse $K d m 5 c$ and $K d m 5 d$ from genomic DNA, generating amplicons differing by $29 \mathrm{bp}$. For the rat, we have identified a common reverse primer for the sex chromosomespecific genes (NC_005120.4 for Kdm5c and NC_024475.1 for Kdm5d) and two unique forward primers, each recognizing a distinct sequence in $\mathrm{Kdm} 5 \mathrm{c}$ or Kdm5d (Figure 1). The PCR reaction generates 250 bp ( $Y$ chromosomespecific) and 692 bp (X chromosomespecific) amplicons, which can be easily resolved by agarose gel electrophoresis.

Initially, genomic DNA was isolated from rat cell lines $\left(2 \times 10^{6}\right.$ cells to 5 $\times 10^{7}$ cells per cell line), a mixture of rat fetal tissues at gestation day (gd) 14.5 and gd 18.5, and tail-tip biopsies from adult outbred and inbred rats. The rat cell lines used in the analyses included PC-12 [CRL-1721; American Tissue Culture Collection (ATCC), Manassas, VA], MMQ (CRL-10609; ATCC), NR8383 (CRL-2192; ATCC), R2C (CCL-97; ATCC), Rcho-1 (16), NB2 (17), RNK16 (18), and TS cells (19). DNA was isolated according to the instructions provided in the Extract-N-Amp tissue PCR kit (XNAT2; Sigma-Aldrich, St. Louis, MO). Each primer (Figure 1) was diluted to $10 \mu \mathrm{M}$ using nucleasefree water. The primer cocktail was prepared by mixing equal volumes of each of the three primers. A PCR reaction volume of $20 \mu \mathrm{l}$ was prepared in 200- $\mu$ l 8-well tube strips (T-3035-1; BioExpress, Kaysville, UT). Each PCR reaction contained $15.35 \mu$ l nucleasefree water (10977-015; Invitrogen; San Diego, CA), $2 \mu \mathrm{l} 10 \times$ DreamTaq green buffer (K1081; Thermo Fisher Scientific, Pittsburgh, PA), $0.4 \mu$ leach of $10 \mathrm{nM}$ dNTP (R0192; Thermo Fisher Scientific), $0.25 \mu$ l DreamTaq DNA polymerase (EP0711; Thermo Fisher Scientific), $1 \mu \mathrm{l}$ primer cocktail, and $1 \mu \mathrm{l}$ genomic DNA template. Amplification was performed

\section{METHOD SUMMARY}

A single-step PCR technique was established to determine the chromosomal sex of rat tissues and cells. Sex determination utilized detection of an X-chromosome-specific gene ( $K d m 5 c)$ and an Y-chromosome-specific gene $(K d m 5 d)$. 


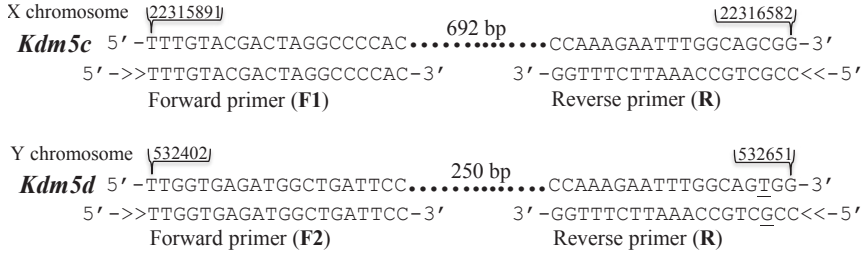

Figure 1. Locations of primers for genes $\mathrm{Kdm} 5 \mathrm{c}$ (X chromosome, NC 005120.4) and Kdm5d (Y chromosome, NC 024475.1) used in rat sex determination. The 19-nucleotide reverse primer (R) for $\mathrm{Kdm} 5 \mathrm{c}$ has a single-nucleotide mismatch (underlined) for $\mathrm{Kdm} 5 \mathrm{~d}$ at nucleotide 532649 of the $Y$ chromosome. Unique forward primers F1 and $\mathrm{F} 2$ correspond to $\mathrm{Kdm} 5 \mathrm{c}$ on the $\mathrm{X}$ chromosome and $\mathrm{Kdm} \mathrm{Cd}$ on the $Y$ chromosome, respectively.

with an initial denaturation step at $95^{\circ} \mathrm{C}$ for 2 min, followed by 35 cycles of denaturation at $95^{\circ} \mathrm{C}$ for $30 \mathrm{~s}$, annealing at $55^{\circ} \mathrm{C}$ for $30 \mathrm{~s}$, and extension at $72^{\circ} \mathrm{C}$ for $42 \mathrm{~s}$, with a final extension step of 7 min at $72^{\circ} \mathrm{C}$ using an Applied Biosystems thermocycler (Model No. 2720; Foster City, CA). PCR products (10 $\mu$ l each) were resolved by electrophoresis at $110 \mathrm{~V}$ for $20 \mathrm{~min}$ in $1 \%$ agarose gels containing $0.02 \%$ ethidium bromide. UV-light imaging was performed in a Gel Doc XR+ instrument (Bio-Rad, Hercules, CA). Representative images from sex determination tests are shown in Figure 2. $X$ chromosome-specific and $Y$ chromosome-specific amplicons could be easily resolved by electrophoresis. Our results demonstrate that this PCR-based procedure for determining sex chromosome status in rat tissues and cells is simple and highly reproducible.

\section{Author contributions}

P.D. and M.J.S. designed the research, analyzed data, and wrote the paper. P.D. performed the research.

\section{Acknowledgments}

We thank Regan Scott and Stacy McClure for assistance. This research was supported by the $\mathrm{NIH}$ (HD020676 and HD079363). This paper is subject to the NIH Public Access Policy.

\section{Competing interests}

The authors declare no competing interests.

\section{References}

1. Soares, M.J., D. Chakraborty, M.A.K. Rumi, T. Konno, and S.J. Renaud. 2012. Rat placentation: an experimental model for investigating the hemochorial maternal-fetal interface. Placenta 33:233-243.

2. Smalley, E. 2016. CRISPR mouse model boom, rat model renaissance. Nat. Biotechnol. 34:893-894.

3. Clayton, J.A. and F.S. Collins. 2014. Policy: NIH to balance sex in cell and animal studies. Nature 509:282-283.

4. Bruce, N.W. and N. Norman. 1975. Influence of sexual dimorphism on foetal and placental weights in the rat. Nature 257:62-63.

5. Kalisch-Smith, J.I., D.G. Simmons, H. Dickinson, and K.M. Moritz. Sexual dimorphism in the formation, function and adaptation of the placenta. Placenta. (In press.) 10.1016/j.placenta.2016.12.008.

6. Clifton, V.L. 2010. Sex and the human placenta: mediating differential strategies of fetal growth and survival. Placenta 31(Suppl.):S33-S39.

7. Bale, T.L. 2011. Sex differences in prenatal epigenetic programming of stress pathways. Stress 14:348-356.

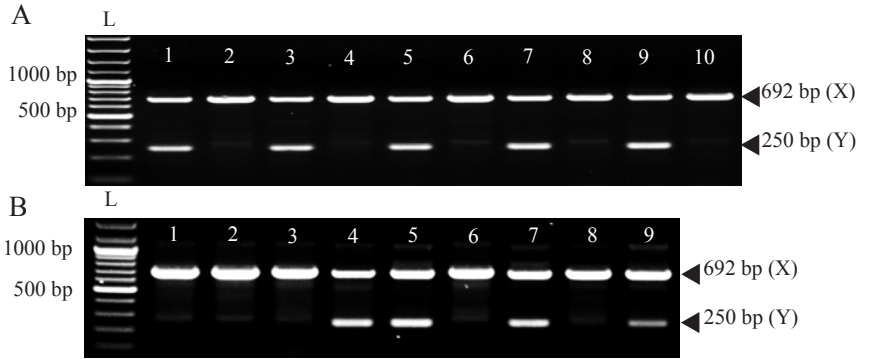

Figure 2. Distinct PCR products corresponding to $X$ and $Y$ chromosome-specific genes. (A) L: Thermo Fisher Scientific GeneRuler 100 bp Plus DNA Ladder; Lane 1: male trophoblast stem (TS) cells; Lane 2: female TS cells; Lane 3: gestation day (gd) 14.5 male fetus; Lane 4: gd 14.5 female fetus; Lane 5: gd 18.5 male fetus; Lane 6: gd 18.5 female fetus; Lane 7: adult male Holtzman Sprague Dawley (HSD) rat; Lane 8: adult female HSD rat; Lane 9: adult male Brown Norway (BN) rat; Lane 10: adult female BN rat. (B) L: GeneRuler 100-bp Plus DNA Ladder; Lane 1: PC-12 (adrenal medulla) cell line; Lane 2: MMQ (pituitary) cell line; Lane 3: Rcho-1 (trophoblast) cell line; Lane 4: NR8383 (lung macrophage) cell line; Lane 5: NB2 ( $T$ cell) cell line; Lane 6: RNK16 (natural killer cell) cell line; Lane 7: R2C (Leydig cell) cell line; Lane 8: adult female HSD rat; Lane 9: adult male HSD rat.

8. Gabory, A., T.J. Roseboom, T. Moore, L.G. Moore, and C. Junien. 2013. Placental contribution to the origins of sexual dimorphism in health and diseases: sex chromosomes and epigenetics. Biol. Sex Differ. 4:5

9. Myatt, L., S. Muralimanoharan, and A. Maloyan. 2014. Effect of preeclampsia on placental function: influence of sexual dimorphism, microRNAs, and mitochondria. Adv. Exp. Med. Biol. 814:133-146.

10. Prudhomme, J. and C. Morey. 2016. Epigenesis and plasticity of mouse trophoblast stem cells. Cell. Mol. Life Sci. 73:757-774.

11. Kunieda, T., M. Xian, E. Kobayashi, T. Imamichi, K. Moriwaki, and Y. Toyoda. 1992. Sexing of mouse preimplantation embryos by detection of $Y$ chromosome-specific sequences using polymerase chain reaction. Biol. Reprod. 46:692-697.

12. An, J., N. Beauchemin, J. Albanese, T.O. Abney, and A.K. Sullivan. 1997. Use of a rat cDNA probe specific for the $Y$ chromosome to detect male-derived cells. J. Androl. 18:289-293.

13. Clapcote, S.J. and J.C. Roder. 2005. Simplex PCR assay for sex determination in mice. Biotechniques 38:702-706.

14. Lambert, J.F., B.O. Beniot, G.A. Colvin, J. Carlson, Y. Deville, and P.J. Quesenberry. 2000. Quick sex determination of mouse fetuses. J. Neurosci. Methods 95:127-132.

15. McFarlane, L., V. Truong, J.S. Palmer, and D. Wilhelm. 2013. Novel PCR assay for determining the genetic sex of mice. Sex Dev. 7:207-211.

16. Faria, T.N. and M.J. Soares. 1991. Trophoblast cell differentiation: establishment, characterization, and modulation of a rat trophoblast cell line expressing members of the placental prolactin family. Endocrinology 129:2895-2906.

17. Gout, P.W., C.T. Beer, and R.L. Noble. 1980. Prolactin-stimulated growth of cell cultures from malignant $\mathrm{Nb}$ rat lymphomas. Cancer Res. 40:2433-2436.

18. Axberg, I., M. Nose, C.W. Reynolds, and H. Wigzell. 1988. Features of the in vitro established rat large granular lymphocyte leukemia RNK-16. Scand. J. Immunol. 27:271-278.

19. Asanoma, K., M.A. Rumi, L.N. Kent, D. Chakraborty, S.J. Renaud, N. Wake, D.S. Lee, K. Kubota, and M.J. Soares. 2011. FGF4-dependent stem cells derived from rat blastocysts differentiate along the trophoblast lineage. Dev. Biol. 351:110-119.

Received 23 January 2017; accepted 27 March 2017.

Address correspondence to Pramod Dhakal or Michael J. Soares, Institute for Reproductive Health and Regenerative Medicine, Department of Pathology \& Laboratory Medicine and Department of Pediatrics, University of Kansas Medical Center, Kansas City, KS 66160. E-mail: pdhakal@kumc.edu or msoares@kumc.edu

To purchase reprints of this article, contact:

biotechniques@fosterprinting.com 